Article

\title{
Suggestion of a New Protection Scheme for a Transmission System Equipped with a Thyristor-Controlled Series Capacitor
}

\author{
Minh-Chau Dinh ${ }^{1}{ }^{\circledR}$, Minh-Quan Tran ${ }^{1}{ }^{\circledR}$, Jae-In Lee ${ }^{1}$, Seok-Ju Lee ${ }^{1}$, Chur Hee Lee ${ }^{2}$, \\ Jongsu Yoon ${ }^{2}$ and Minwon Park ${ }^{1, *}$ \\ 1 Department of Electrical Engineering, Changwon National University, Changwon 51140, Korea; \\ thanchau7787@gmail.com (M.-C.D.); minhquan.hcmut@gmail.com (M.-Q.T.); j9993235@gmail.com (J.-I.L.); \\ kikigod1039@gmail.com (S.-J.L.) \\ 2 Korea Electric Power Research Institute, Seoul 34056, Korea; supper7245@naver.com (C.H.L.); \\ jongsu.yoon@kepco.co.kr (J.Y.) \\ * Correspondence: pakumw1@gmail.com; Tel.: +82-55-281-3150
}

Received: 3 May 2019; Accepted: 10 June 2019; Published: 12 June 2019

check for updates

\begin{abstract}
A thyristor-controlled series capacitor (TCSC) is employed to a transmission line in order to enhance the usable capacity of the present as well as upgraded lines, improve system stability, reduce losses, and improve power flow control capability. However, in an abnormal situation, the TCSC may transit from the existing operation mode to the other mode according to its control system and protection strategy. There is much difference in the impedance of the TCSC between each mode. This threatens the reliability of the conventional protection system, especially the distance relay, that works based on the measurement of line impedance. In this paper, we suggest a new protection scheme for a distance relay of a transmission line equipped with a TCSC. In the suggested method, in order to mitigate the effect of the TCSC in the fault loop, the TCSC injected voltage is subtracted from the measured phase voltage before supplying the voltage signal to the distance relay. The suggested scheme was verified by a real time digital simulator (RTDS)-based closed-loop test bed of a protective relay. The effect of the TCSC in the fault loop was completely mitigated. The distance relay works properly with the suggested scheme.
\end{abstract}

Keywords: fixed series capacitor (FSC); new protection scheme; RTDS; transmission system; TCSC

\section{Introduction}

In recent years, the increase in power demands requires the expansion of power generation and transmission. However, the expansion meets the limit due to environment and resource restriction. To overcome this problem, flexible alternating current transmission system (FACTS) technology, such as thyristor-controlled series capacitors (TCSC) and high voltage alternating current (HVDC), is one of the possible solutions because it enhances the usable capacity of the transmission facilities and system reliability. TCSC is one of the most critical devices in the FACTS family. By compensating the transmission line impedance, the TCSC enhances the power transfer capability and opens up the power control capability for the present and upgraded lines [1-3].

A TCSC consists of a capacitor (C) connected in parallel with a thyristor-controlled reactor (TCR). The TCSC module also has different protective elements, such as a metal oxide varistor (MOV) or a bypass circuit breaker (CB), connected in parallel with its main circuit. The TCSC has four operation modes: bypassed-thyristor mode, blocked-thyristor mode, capacitive vernier mode, and inductive vernier mode. In normal operation, the TCSC is operated at the capacitive vernier mode to compensate the transmission line impedance [4]. In order to protect the TCSC capacitor from over-voltage, the MOV 
connected in parallel with the TCSC capacitor will operate. Besides this, in some severe situation like faults or equipment malfunctions, if the MOV cannot handle the TCSC capacitor over-voltage completely, the bypass $\mathrm{CB}$ will close to bypass the high current. The bypass $\mathrm{CB}$ is also activated when the energy of the MOV exceeds its certain threshold level.

During a fault, different operation modes could incorporate with the TCSC protection equipment. Therefore, the operation modes are as follows: blocked mode with/without MOV, capacitive mode with/without MOV, TCSC bypass, CB bypass.

Depending on the pre-fault and fault conditions, the TCSC may switch from the existing mode to the other mode according to its control and protection strategy. There is much difference in the impedance of the TCSC between each mode, so the transition from one mode to another may cause malfunctions of the conventional distance relay, such as forward over-reach, reverse over-reach, and direction malfunction [5].

Many research papers have indicated that the TCSC affects the protection of its line as well as the protection of adjacent lines. The problems are over-reach, miscoordination in primary and backup protections, and directional malfunction [6-8]. Some approaches have been introduced to overcome the problems. In Ref. [7], the authors introduced a new setting for a distance relay, in which the new setting impedance was set to the conventional setting impedance minus the biggest compensated reactance of the TCSC. This method can reduce the misoperation of the distance relay in the external fault and reverse direction fault, however, the protection range is reduced. In Ref. [9], the authors introduced the distance protection setting method based on the modified particle swarm optimization (MPSO) techniques. The MPSO was used to calculate the distance relay setting for the inductive and capacitive modes of the TCSC. However, how the distance relay works with two different settings, and the adjustment of the relay setting when the TCSC changes from the boost modes (inductive and capacitive) to the bypass mode, or when the operation modes are incorporated with the protection equipment was not discussed. Reference [10] described a new high-speed MHO distance protection scheme for single-line-to-ground faults in the TCSC line. In this scheme, the TCSC reactance is subtracted from the total fault impedance to mitigate the effect of the TCSC in the fault loop. However, the TCSC reactance was defined based on the firing angle from the TCSC, so the TCSC impedance will not be estimated correctly when the protection equipment, like the MOV or bypass $\mathrm{CB}$, operates. In Ref. [11], modified communication-aided distance protection schemes were introduced. However, the protection zone of those methods is just the main protected line; they cannot be used as back-up protection for the adjacent lines. In Ref. [12], the average voltage and current-based fast protection scheme for detecting the fault direction was introduced. [13] presented an impedance measurement at multiple frequencies for detecting whether or not the series capacitor is in the fault loop. The detection of a TCSC in the fault loop was not discussed in detail. In Ref. [14], in order to eliminate the effect of the TCSC, a fault current limiter (FCL) was supposed to be installed in series with the TCSC. With this method, an additional device is needed. In conclusion, the impedance measurements-based protection schemes still have some problems. They are not able to overcome the mal-operation of the distance relay in all possible operation modes of the TCSC. The protection range is reduced or the back-up protection function for the adjacent lines is lost. After all, the installation of TCSC in a transmission system will threaten the reliability and security of the power system if the existing protection system of the transmission line is not adjusted or replaced.

So, in this paper, we suggest a new protection scheme named as the voltage compensator scheme for a transmission line equipped with a TCSC. This method can eliminate the effect of the TCSC in the fault loop and secure the proper operation of the distance relay in all possible operation modes of the TCSC without modifying the relay setting. In the suggested method, the TCSC injected voltage is subtracted from the measured phase voltage to eliminate the effect of the TCSC in the fault loop. We also implemented a real time digital simulator (RTDS)-based closed-loop test of a protective relay that incorporates a commercial protective relay device with the simulated utility grid system to verify the suggested method. 
The simulation demonstrated that the effect of TCSC in the fault loop was completely mitigated and the distance relay works properly with the suggested scheme.

\section{The Operating Principle and Parameters of TCSC}

\subsection{The Operating Principle of TCSC}

There are four operation modes of a TCSC: bypassed-thyristor mode, blocked-thyristor mode, capacitive vernier mode, and inductive vernier mode. In the bypassed mode, the thyristors conduct entirely with a conduction angle of $180^{\circ}$. The TCSC module behaves like a parallel capacitor-inductor combination. In the blocked-thyristor mode, the TCSC controller blocks the firing pulses to the thyristor valves. The thyristor current is zero. It is also known as the waiting mode. The capacitive vernier mode allows the TCSC to behave as a continuously controllable capacitive reactance. In this mode, the TCSC controller will adjust the thyristor firing angle in a proper range. In the inductive vernier mode, the TCSC behaves as a continuously controllable inductive reactance. In general, the inductive vernier mode is not used.

In order to protect the TCSC capacitor from over-voltage, the MOV that is connected in parallel with the TCSC capacitor will operate. Also, in some severe situations, like faults or equipment malfunctions, if the MOV cannot handle the TCSC capacitor over-voltage completely, the bypass CB installed across the TCSC module will close to bypass the high current. This mode is also activated when the energy of the MOV exceeds its certain threshold level.

Figure 1 shows the configuration of a $345 \mathrm{kV}$ transmission system, including a series compensation device. The series compensation device is composed of an FSC and a TCSC. The FSC and TCSC have their MOVs. The bypass CB is across both the FSC and TCSC to protect them from over-voltage. Figure 2 shows the mode sequence of the FSC and TCSC during a fault. If the fault current is more significant than 1.5 times the rated current, the TCSC will change to the bypassed-TCSC mode. If the fault current is more significant than 2.2 times the rated current or the energy of the FSC MOV or TCSC MOV exceeds the threshold value, the TCSC will switch to the bypassed-CB mode. During a fault, different modes of operation could incorporate with the TCSC protection equipment. The possible operation modes and the TCSC impedance characteristics are summarized in Table 1.

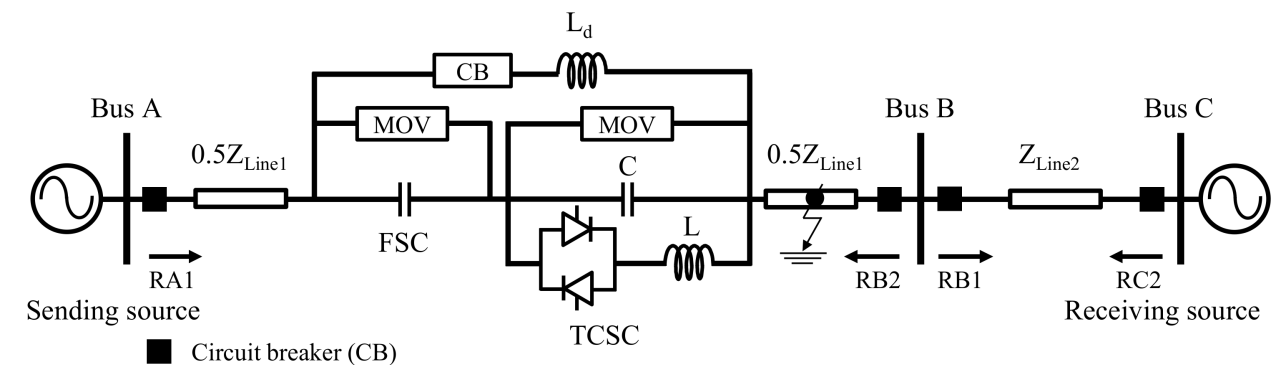

Figure 1. The configurations of a $345 \mathrm{kV}$ transmission system, including the fixed series capacitor (FSC) and thyristor-controlled series capacitor (TCSC). 


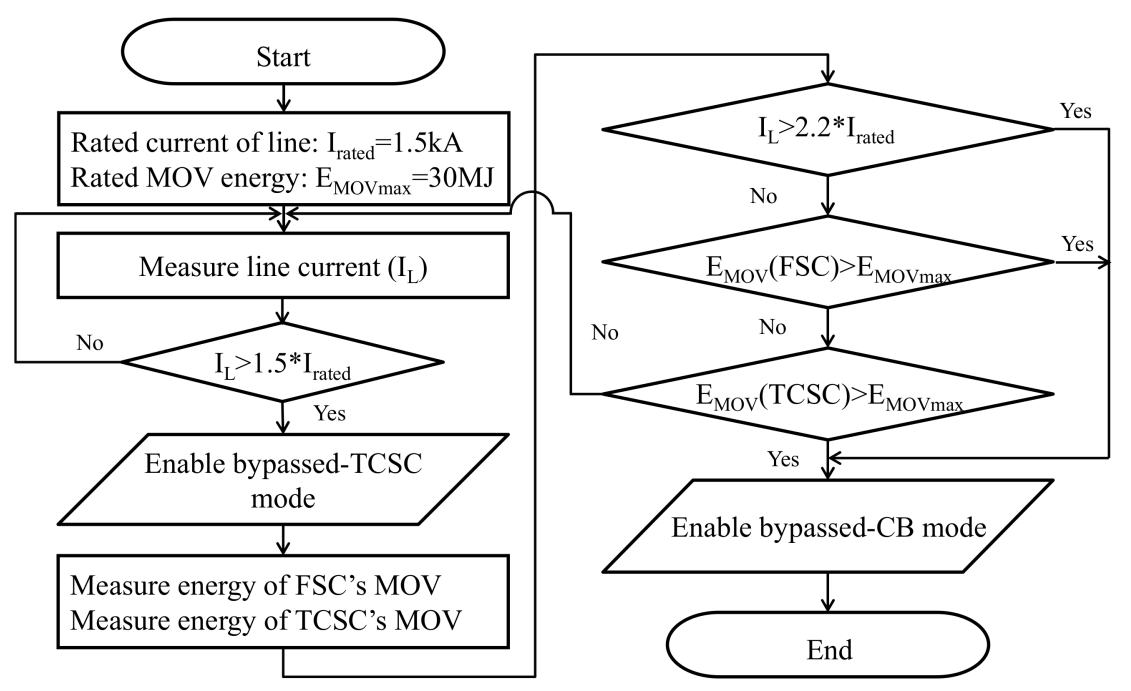

Figure 2. Mode sequence of the TCSC during the fault.

Table 1. Operation modes of the TCSC and its impedance characteristics.

\begin{tabular}{ccc}
\hline No & Mode & Impedance Characteristics \\
\hline 1 & Blocked mode without TCSC & $-\mathrm{j} \mathrm{X}_{\mathrm{C}}$ \\
2 & Blocked mode with TCSC & $-\mathrm{j} \mathrm{X}_{\mathrm{C}}$ in parallel with $\mathrm{R}_{\mathrm{MOV}}$ \\
3 & Capacitive mode with TCSC & {$[1 \sim 3] \times\left(-\mathrm{j} \mathrm{X}_{\mathrm{C}}\right)$} \\
4 & Capacitive mode without TCSC & {$[1 \sim 3] \times\left(-\mathrm{j} \mathrm{X}_{\mathrm{C}}\right)$ in parallel with $\mathrm{R}_{\mathrm{MOV}}$} \\
5 & TCSC Bypass & $-\mathrm{j} \mathrm{X}_{\mathrm{C}}$ in parallel with $\mathrm{j} \mathrm{X}_{\mathrm{L}}$ \\
6 & CB Bypass & $\sim 0$ \\
\hline
\end{tabular}

\subsection{Configuration of the $345 \mathrm{kV}$ Transmission System equipped with the TCSC}

The $345 \mathrm{kV}$ test power system equipped with a $345 \mathrm{kV}$ TCSC is depicted in Figure 1. The system includes two transmission lines and three buses. Bus A is connected to a sending source, and bus $\mathrm{C}$ is connected to a receiving source. The phase angle difference between the sending and receiving sources causes the power flow in the system. The lengths of line 1 and line 2 are $200 \mathrm{~km}$ and $100 \mathrm{~km}$, respectively. Moreover, their distributed parameters are summarized in Table 2. Series compensation devices include the FSC and TCSC. The capacitance of the FSC capacitor is $90.35 \mu \mathrm{F}$, corresponding to $40 \%$ compensation degree. The compensation devices are located in the middle of line 1 .

Table 2. Parameters of the $345 \mathrm{kV}$ transmission system.

\begin{tabular}{cccc}
\hline Component & Parameters & Value & Unit \\
\hline \multirow{4}{*}{ Sending source } & Voltage magnitude & 345 & $\mathrm{kV}$ \\
& Phase angle & 30 & Degree \\
& Positive sequence impedance & $1.3945+\mathrm{j} 15.9391$ & $\Omega$ \\
& Zero sequence impedance & $7.454+\mathrm{j} 27.8287$ & $\Omega$ \\
Receiving source & System frequency & 60 & $\mathrm{~Hz}$ \\
& Voltage magnitude & 345 & $\mathrm{kV}$ \\
& Phase angle & 0 & Degree \\
& Positive sequence impedance & $1.3945+\mathrm{j} 15.9391$ & $\Omega$ \\
& Zero sequence impedance & $7.454+\mathrm{j} 27.8287$ & $\Omega$ \\
& Positive sequence impedance & $0.037+\mathrm{j} 0.367$ & $\Omega / \mathrm{km}$ \\
& Zero sequence impedance & $0.296+\mathrm{j} 1.102$ & $\Omega / \mathrm{km}$ \\
& Length of line 1 & 200 & $\mathrm{~km}$ \\
& Length of line 2 & 100 & $\mathrm{~km}$ \\
\hline
\end{tabular}


As shown in Figure 1, the typical configuration of a TCSC includes two critical parts. One is the controllable-segment, which is composed of a fixed capacitor (FC) and a TCR. The other is protection devices, including the metal oxide varistor (MOV) and bypass $\mathrm{CB}$ branch. Table 3 shows the parameters of the $345 \mathrm{kV}$ TCSC, and Table 4 shows its operating characteristics [15].

Table 3. The 345kV TCSC parameters.

\begin{tabular}{cccc}
\hline Parameters & Symbol & Value & Unit \\
\hline Minimum reactance of TCSC & $\mathrm{X}_{\mathrm{C}}$ & 3.67 & $\Omega$ \\
The capacitance of the fixed capacitor & $\mathrm{C}$ & 722.77 & $\mu \mathrm{F}$ \\
The inductance of the TCR inductor & $\mathrm{L}$ & 1.56 & $\mathrm{mH}$ \\
\hline
\end{tabular}

Table 4. Operation characteristics of the TCSC.

\begin{tabular}{cccc}
\hline Parameters & Min Value & Max Value & Unit \\
\hline Percentage compensation & 5 & 15 & $\%$ \\
Firing angle & 180 & 148 & Degree \\
Reactance of TCSC (blocked-mode) & $-\mathrm{j} 3.67$ & - & $\Omega$ \\
Reactance of TCSC (capacitive mode) & $-\mathrm{j} 3.67$ & $-\mathrm{j} 11.01$ & $\Omega$ \\
Reactance of TCSC (bypass mode) & $\mathrm{j} 0.7$ & - & $\Omega$ \\
\hline
\end{tabular}

The FSC and TCSC are equipped with two MOVs and a bypass CB as protective devices. MOV is a voltage-dependent, nonlinear resistor that can provide a new path for bypassing the fault current when the TCSC or FSC capacitor over-voltage occurs. The following exponential equation represents the MOV voltage (v)-current (i) characteristic [8,16]:

$$
i_{M O V}=I_{r e f}\left(\frac{v_{M O V}}{V_{r e f}}\right)^{n},
$$

where $i_{M O V}$ and $v_{M O V}$ are the MOV current and voltage, respectively, $I_{r e f}$ and $V_{\text {ref }}$ are the reference quantities, $n$ is the exponent of the characteristics.

A circuit breaker (CB) is installed across both the FSC and the TCSC to bypass it if a very high fault current or malfunction occurs. Moreover, a current limiting inductor, $L_{d}$, is installed in series with the bypass $\mathrm{CB}$ to limit the fault current. Table 5 represents the parameters of MOVs and bypass CB branch.

Table 5. The parameters of the FSC and TCSC protection devices.

\begin{tabular}{cccc}
\hline Component & Parameters & Value & Unit \\
\hline CB Bypass & Current limiting reactor $\left(\mathrm{L}_{\mathrm{d}}\right)$ & 0.1 & $\mathrm{mH}$ \\
& MOV reference current & 6.5 & $\mathrm{kA}$ \\
FSC & MOV reference voltage & 156 & $\mathrm{kV}$ \\
& MOV exponent & 16 & \\
& Maximum MOV energy & 30 & $\mathrm{MJ}$ \\
TCSC & MOV reference current & 2.5 & $\mathrm{kA}$ \\
& MOV reference voltage & 60 & $\mathrm{kV}$ \\
& MOV exponent & 16 & \\
& Maximum MOV energy & 30 & $\mathrm{MJ}$ \\
\hline
\end{tabular}

Figure 3 shows the block diagram of a typical TCSC controller. The TCSC controller is based on a proportional-integral (PI) regulator. It can be operated in the constant-impedance control, constant-current control, or power control [17]. 


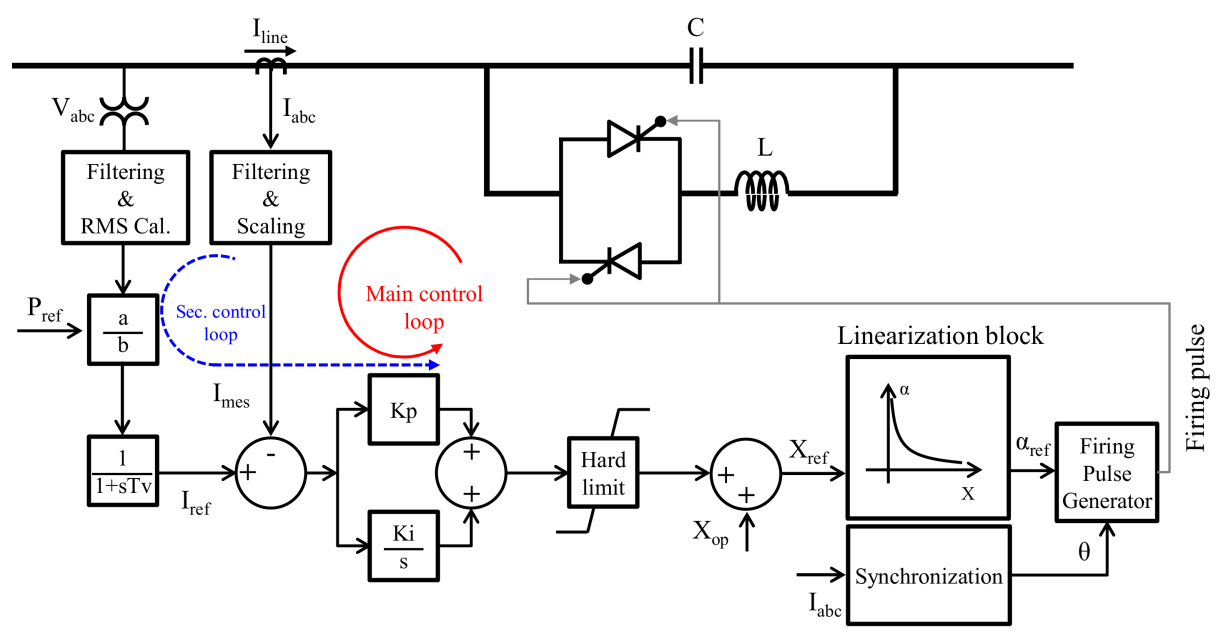

Figure 3. Typical block diagram of the TCSC controller.

\section{Design of New Protection Scheme for the Transmission System Equipped with the TCSC}

\subsection{The Influence of TCSC on Distance Protection of the Transmission Line}

As shown in Figure 1, the TCSC is in the middle of the transmission line 1. The impedance beyond the TCSC is measured by the relay RA1 at the bus A of line 1, as [5]:

$$
Z_{m}=d Z_{1 L 1}+Z_{T C S C}
$$

where $Z_{m}$ is the impedance measured by the relay $(\Omega), d$ is the fault location (pu), $Z_{\text {TCSC }}$ is the TCSC impedance $(\Omega)$, and $Z_{1 L 1}$ is the positive-sequence impedance of line $1(\Omega)$.

Dividing both sides of (2) by $Z_{m}^{\prime}=d Z_{1 L 1}$, we obtain:

$$
\frac{Z_{m}}{Z_{m}^{\prime}}=1+\frac{k}{d^{\prime}}
$$

where $k=Z_{T C S C} / Z_{1 L 1} . k$ represents the compensation degree when the TCSC is operated in the capacitive mode.

Figure 4 shows $Z_{m} / Z_{m}^{\prime}$ versus $k$ for different values of fault location $d$. The figure indicates that the influence of a TCSC is critical to both reach and directionality of relay. For example, in the case of $50 \%$ compensation factor, when the fault occurs at the remote end of the line, i.e., $d=1.0$, the relay over-reaches and $Z_{m}=0.5 Z_{1 L 1}$ instead of $Z_{1 L 1}$. As seen in Figure 4 , for $0.5<d<0.55$, the relay would not see the fault in a forward direction, even for a normal operating point, before the TCSC mode changes. In the bypass mode, $Z_{T C S C}$ is positive, and the relay under-reaches slightly. Table 6 indicates the operation of distance relay under the different operation modes of the TCSC. 


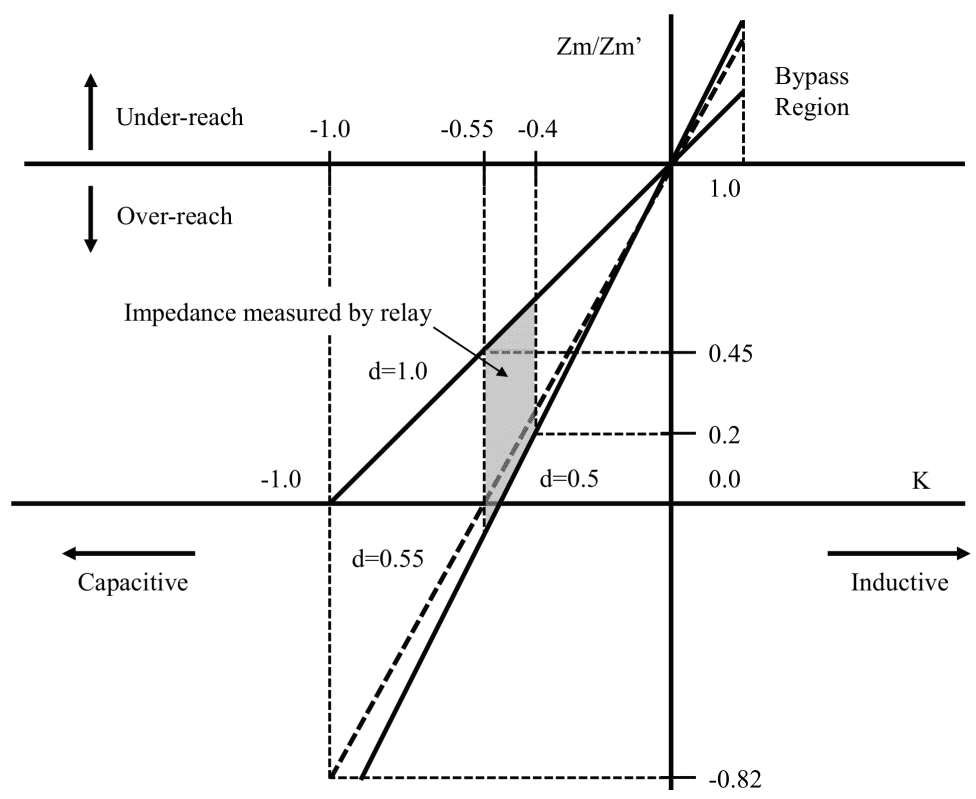

Figure 4. Impedance measured by the relay for a three-phase fault with different fault location and different compensation degree.

Table 6. Operation of distance relay under the different operation modes of the TCSC.

\begin{tabular}{ccc}
\hline No & Mode & Distance Relay Operation \\
\hline 1 & Blocked mode without TCSC & Over-reach \\
2 & Blocked mode with TCSC & Over-reach less than case 1 \\
3 & Capacitive mode with TCSC & Over-reach \\
4 & Capacitive mode without TCSC & Over-reach less than case 3 \\
5 & TCSC Bypass & Under-reach slightly \\
6 & CB Bypass & Normal \\
\hline
\end{tabular}

3.2. TCSC Voltage Compensator Scheme for Distance Relays in the presence of the TCSC

\subsubsection{Voltage Compensator}

The impact of the TCSC on the fault loop can be mitigated if the TCSC voltage $\left(v_{T C S C}(t)\right)$ is subtracted from the measured phase voltage $v(t)$ :

$$
v_{c o m}(t)=v(t)-v_{T C S C}(t)
$$

Then, the impedance measured by the relay is re-calculated. Figure 5a presents the sequence network interconnections of a phase-to-phase fault. For a phase-to-phase fault between phase B and phase $\mathrm{C}$ beyond the TCSC, phase B and C fault current are calculated as:

$$
\begin{aligned}
& I_{B}=a^{2} I_{1}+a I_{2}=\left(a^{2}-a\right) I_{1} \\
& I_{C}=a I_{1}+a^{2} I_{2}=\left(a-a^{2}\right) I_{1}
\end{aligned},
$$

where operator $\mathrm{a}=\mathrm{e}^{\mathrm{j} 120^{\circ}}, I_{1}$, and $I_{2}$ are positive- and negative-sequence components of the line current, respectively.

The sequence components of the voltage measured by the relay are:

$$
\begin{aligned}
& V_{1}=I_{1}\left(\mathrm{~d} \times \mathrm{Z}_{1 \mathrm{~L} 1}+\mathrm{Z}_{1 T C S C}\right) \\
& V_{2}=I_{2}\left(\mathrm{~d} \times \mathrm{Z}_{2 \mathrm{~L} 1}+\mathrm{Z}_{2 T C S C}\right)
\end{aligned},
$$


where $Z_{1 L 1}$ and $Z_{2 L 1}$ are the positive- and negative-sequence components of line 1 impedance, respectively, and $Z_{1 T C S C}$ and $Z_{2 T C S C}$ are the positive- and negative-sequence components of the TCSC impedance, respectively.

Thus, we have:

$$
\begin{aligned}
& V_{1 \text { comp }}=V_{1}-V_{1 T C S C}=I_{1} \times \mathrm{dZ}_{1 \mathrm{~L} 1} \\
& V_{2 \text { comp }}=V_{2}-V_{2 T C S C}=I_{2} \times \mathrm{dZ}_{2 \mathrm{~L} 1} .
\end{aligned}
$$

Phase $B$ and phase $C$ voltage are calculated as:

$$
\begin{aligned}
& V_{B}=a^{2} V_{1 \text { comp }}+a V_{2 \text { comp }}=\left(a^{2}-a\right) I_{1} d Z_{1 L 1} \\
& V_{C}=a V_{1 \text { comp }}+a^{2} V_{2 \text { comp }}=\left(a-a^{2}\right) I_{1} d Z_{1 L 1}
\end{aligned} .
$$

When the voltage across the TCSC is subtracted from the measured phase voltage, the impedance measured by the relay is:

$$
Z_{B C}=\frac{V_{B}-V_{C}}{I_{B}-I_{C}}=\frac{\left[\left(a^{2}-a\right)-\left(a-a^{2}\right)\right] I_{1} d Z_{1 L 1}}{\left[\left(a^{2}-a\right)-\left(a-a^{2}\right)\right] I_{1}}=d Z_{1 L 1} .
$$

Figure $5 \mathrm{~b}$ presents the sequence network interconnections of a single-line-to-ground fault. The sequence components of the voltage measured by the relay are:

$$
\begin{aligned}
& V_{1}=I_{1}\left(\mathrm{~d} \times \mathrm{Z}_{1 \mathrm{~L} 1}+Z_{1 T C S C}\right)=I_{1} \times d Z_{1 L 1}+V_{1 T C S C} \\
& V_{2}=I_{2}\left(\mathrm{~d} \times \mathrm{Z}_{2 \mathrm{~L} 1}+Z_{2 T C S C}\right)=I_{2} \times d Z_{2 L 1}+V_{2 T C S C} \\
& V_{0}=I_{0}\left(\mathrm{~d} \times \mathrm{Z}_{0 \mathrm{~L} 1}+Z_{0 T C S C}\right)=I_{0} \times d Z_{0 L 1}+V_{0 T C S C}
\end{aligned}
$$

where $Z_{O L 1}$ and $Z_{0 T C S C}$ are the zero-sequence component of the line impedance and TCSC impedance, respectively. $V_{1 T C S C}, V_{2 T C S C}$, and $V_{0 T C S C}$ are the sequence components (positive, negative, and zero) of the TCSC voltage.

In the case of the single-line-to-ground fault, the zero-sequence current $\left(I_{0}\right)$, the positive- sequence current $\left(I_{1}\right)$, and the negative-sequence current $\left(I_{2}\right)$ are equal, and $Z_{1 L 1}$ is supposed to equal $Z_{2 L 1}$, so that we can have:

$$
\begin{gathered}
V_{A}=V_{1}+V_{2}+V_{3}=I_{1}\left(2 d Z_{1 L 1}+Z_{0 L 1}\right)+V_{T C S C A} ; \\
I_{A}=I_{1}+I_{2}+I_{3}=3 I_{1} .
\end{gathered}
$$

The zero-sequence compensation (ZSC) factor is defined as:

$$
K_{0}=\frac{Z_{0 L 1}-Z_{1 L 1}}{3 Z_{1 L 1}}
$$

Finally, we have:

$$
Z_{A N}=\frac{V_{\mathrm{A}}-V_{T C S C A}}{\left(1+K_{0}\right) I_{A}}=d Z_{1 L 1} .
$$

For the three-phase fault and the double phase-to-ground fault, the obtained result is the same as equation (9). Equations (9) and (14) demonstrate that the impedance measured by the relay is proportional to the distance from the fault point to the relay location only if the TCSC voltage is subtracted from the measured phase voltage. So, with the voltage compensator scheme, the setting for a distance relay of a transmission line equipped with a TCSC is designed based on the same manner that we use for the distance relay of the transmission line without the TCSC. 


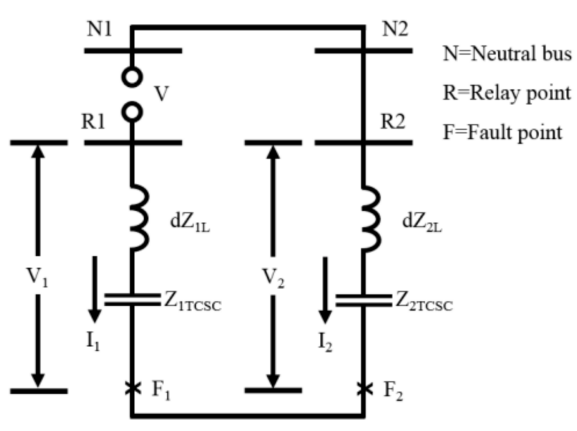

(a)

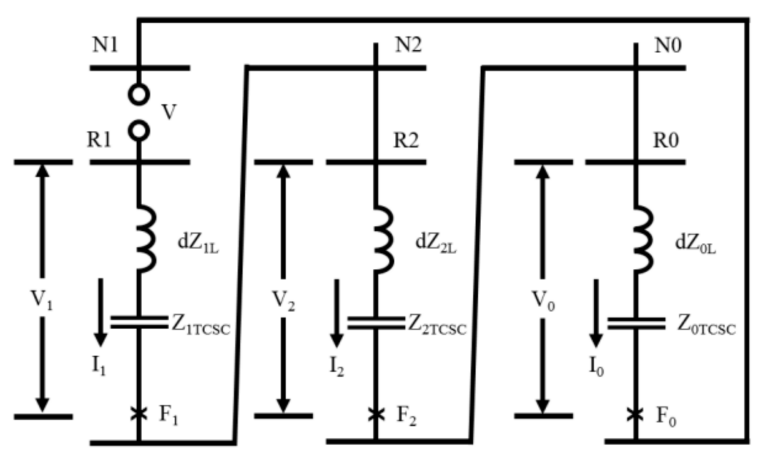

(b)

Figure 5. Sequence network interconnections: (a) phase-to-phase fault; (b) single-phase-to-ground fault.

\subsubsection{Detection of the TCSC in the Fault Loop}

We consider the relay RA1 of line 1, as shown in Figure 1. When a fault occurs between the relay and the TCSC, the TCSC will not affect the impedance measurement of the relay RA1. However, if a fault occurs beyond the TCSC, the corresponding voltage across the TCSC $\left(v_{T C S C}(t)\right)$ should be subtracted from the measured phase voltage $v(t)$ in order to mitigate the effect of TCSC, as described in Section 3.2.1. Thus, it is necessary to develop an algorithm that can detect whether the TCSC is inside or outside of the fault loop in order to decide when the voltage across TCSC should be compensated.

Two current transformers (CT) with the same type and ratio are installed at the bus A and the middle of line 1, as shown in Figure 6. When the fault occurs beyond the TCSC or the TCSC is in the fault loop, the operating current $\left(I_{O P}\right)$ flowing through the over-current relay $(\mathrm{OC})$ is very small but not zero, due to the non-homogeneous characteristics of the CTs, as described in Figure 6a. When a fault occurs between the bus A and the series compensation devices, the operating current $\left(I_{O P}\right)$ is the sum of the input current feeding the fault, and it is quite significant. In this case, the TCSC is out of the fault loop, as depicted in Figure 6b. Based on this, we proposed the control logic in Figure 7. When $I_{O P}$ is higher or equal the threshold value, the output signal of the comparator (Ctrl) is 1 -this means that the TCSC is out of the control loop. Thus, compensated voltage $\left(v_{\text {com }}(t)\right)$ equals the phase voltage $(v(t))$. In contrast, when the TCSC is in the fault loop, "Ctrl" is 0 and the compensated voltage $\left(v_{\text {com }}(t)\right)$ equals phase voltage $(v(t))$ minus the TCSC voltage $\left(v_{T C S C}(t)\right)$.

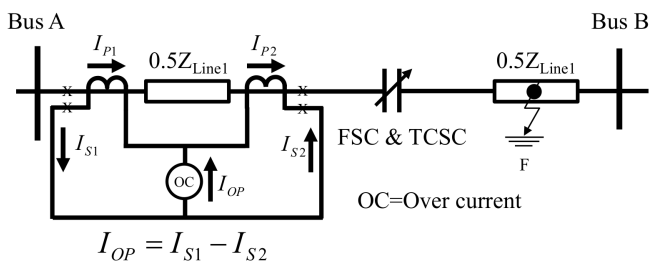

(a)

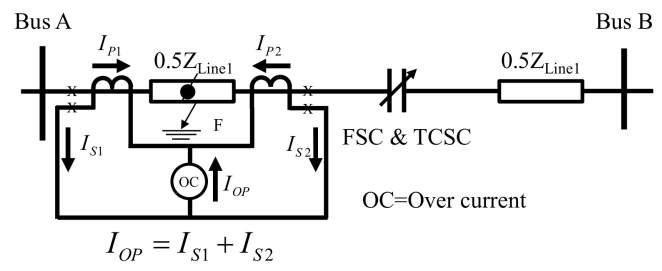

(b)

Figure 6. Detection of TCSC in the fault loop: (a) TCSC is in the fault loop; (b) TCSC is out of the fault loop. 


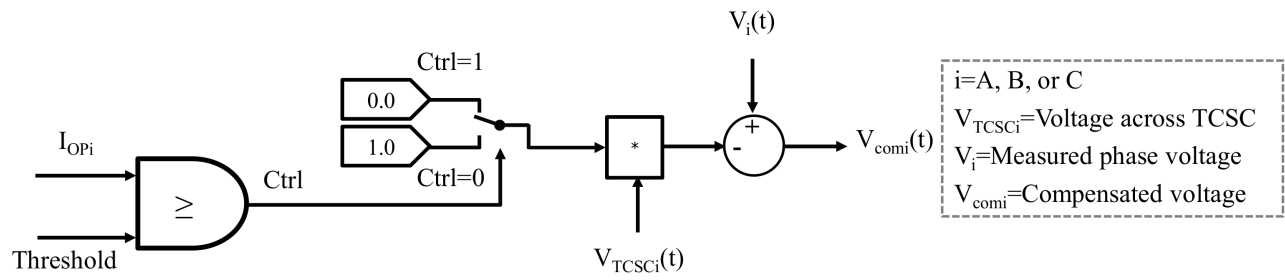

Figure 7. Control logic for the detection of TCSC in the fault loop.

\subsection{Distance Relay Setting}

For the test system in Figure 1, the main setting design of the distance relay RA1 is presented in Table 7 .

Table 7. Design setting of the distance relay RA1.

\begin{tabular}{cccc}
\hline Setting Contents & Setting Design & Value & Unit \\
\hline Zone 1 Impedance Reach & $Z_{1}=0.85 Z_{1 L 1}$ & 62.7 & $(\Omega$, Pri. $)$ \\
Zone 2 Impedance Reach & $Z_{2}=Z_{1 L 1}+0.5 Z_{1 L 2}$ & 92.2 & $(\Omega$, Pri.) \\
Zone 3 Impedance Reach & $Z_{3}=Z_{1 L 1}+1.25 Z_{1 L 2}$ & 119.85 & $(\Omega$, Pri.) \\
Zone 1 ZSC Factor & $K_{01}=\left(Z_{0 L 1}-Z_{1 L 1}\right) /\left(3 Z_{1 L 1}\right)$ & $0.7(\mathrm{Mag})$ & \\
Forward ZSC Factor & $K_{0 F}=K_{01}$ & $-13.62^{\circ}$ (Phase) & \\
Zone 1 Time Delay & $\mathrm{T}_{1 \mathrm{D}}$ & 0 & Cycles \\
Zone 2 Time Delay & $\mathrm{T}_{2 \mathrm{D}}$ & 20 & Cycles \\
Zone 3 Time Delay & $\mathrm{T}_{3 \mathrm{D}}$ & 100 & Cycles \\
\hline
\end{tabular}

$Z_{1 L 1}$ and $Z_{0 L 1}$ denote the positive- and zero-sequence impedances of the transmission line 1 , respectively. $Z_{1 L 2}$ is the positive-sequence impedance of the transmission line 2 in Figure 1.

\section{RTDS-Based Closed-Loop Test Bed of a Distance Relay}

In order to confirm the suggested protection scheme, we performed the RTDS-based hardware in the loop simulation of a protective relay. As shown in Figure 8, the RTDS-based closed-loop test of a protective relay includes the test power system modeling using RTDS, fault detection, and feedback of the operation signals of the circuit breakers in the RTDS [18].

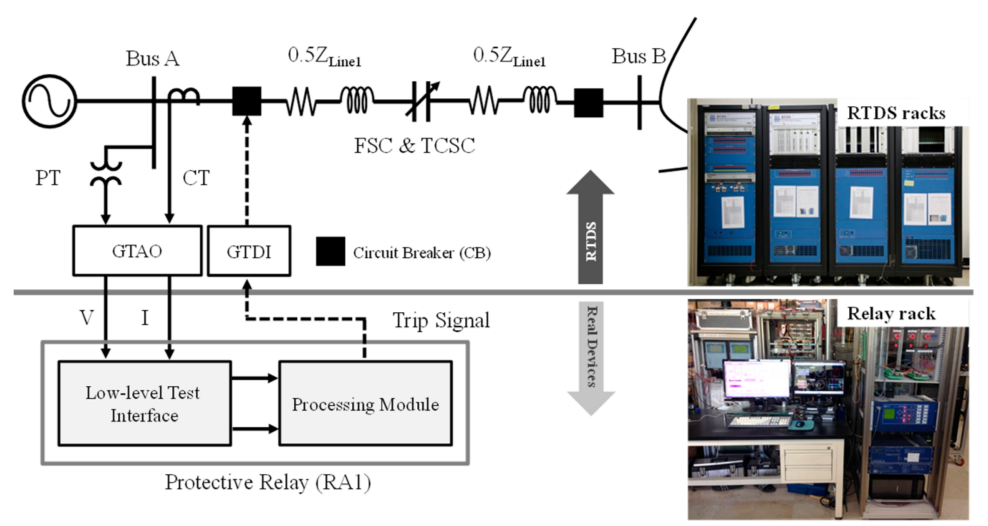

Figure 8. Closed-loop test of a protective relay using a real time digital simulator (RTDS).

(1) The test power system modeling using RTDS

The test power system, including transmission lines, voltage sources, and circuit breaker (CB), is modeled using the RTDS library standard components. The models of the $345 \mathrm{kV}$ FSC and TCSC were also developed and modeled in the RTDS. 
(2) Fault detection

The current and voltage signals generated from RTDS are sent to the processing module of the relay via the gigabit transceiver analog output (GTAO) card of the RTDS and low-level test interface of an SEL-411L. Based on these signals, the practical relay SEL-411L will detect whether a fault occurs in the system. The TCSC voltage compensator scheme was developed and implemented in a real-time simulation environment (RTDS). Only the compensated voltages are sent to the relay SEL-411L.

(3) Feedback of the operation signals of the circuit breakers in the RTDS

The "OPEN" and "CLOSE" signals are sent from the relay to the RTDS via the gigabit transceiver digital input (GTDI) card. In this study, the relay model SEL-411L of Schweitzer Engineering Laboratories was incorporated with the test system model in the RTDS via the interface cards.

Figure 9 depicts the RTDS modeling of the $345 \mathrm{kV}$ test power system with the FSC and the TCSC.

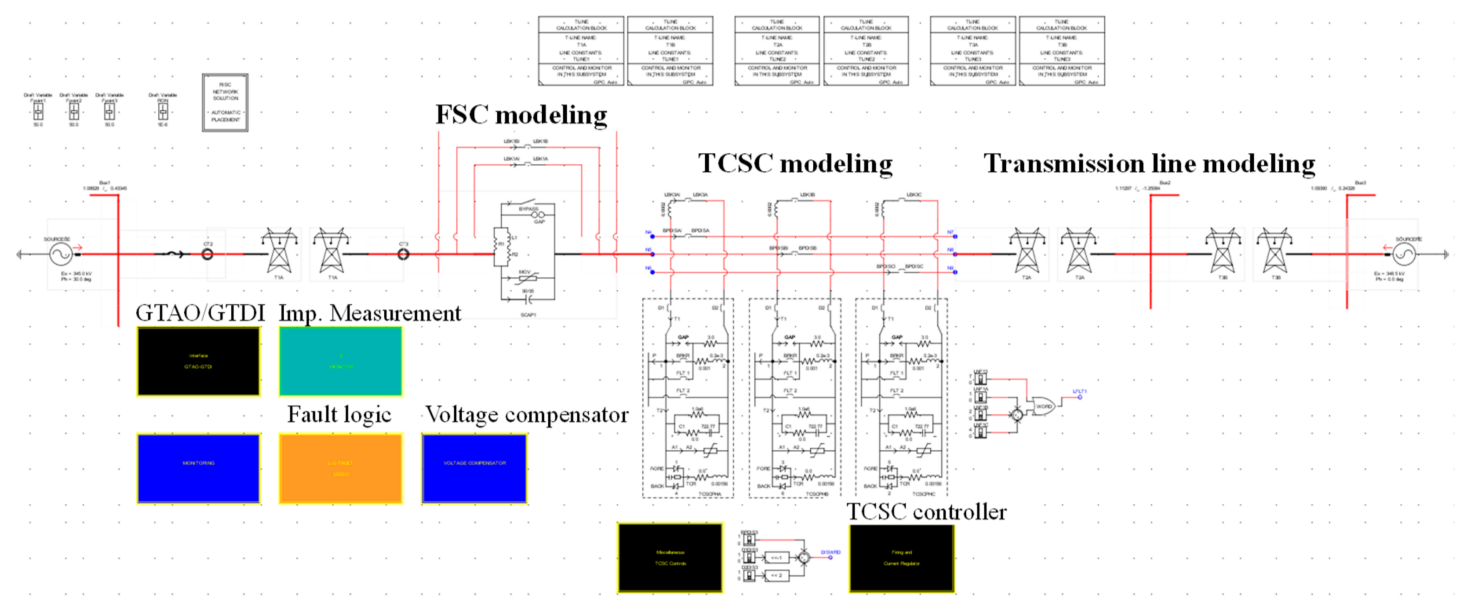

Figure 9. RTDS modeling of a $345 \mathrm{kV}$ transmission system with the FSC and TCSC.

\section{Results and Discussion}

\subsection{The Test Results}

In order to demonstrate the effectiveness of the proposed scheme, the operating characteristics of the protection relay RA1 with both the conventional and proposed schemes were analyzed with different fault types and fault location along line $\mathrm{AB}$ and line $\mathrm{BC}$. Within this study, the fault resistance was assumed to be a constant of $0.001 \mathrm{ohms}$. Before the fault, the TCSC was being operated under the capacitive mode, and its percentage compensation $\left(k_{T C S C}\right)$ was $10 \%$. The percentage compensation of the FSC $\left(k_{F S C}\right)$ was a constant of $40 \%$-the total compensation was $50 \%$.

Figure 10 represents the analysis of operating characteristics of the protection relay RA1 for the three-phase fault in the middle of line 1 beyond the TCSC. Although the protection relay RA1 trips at zone 1 for both the conventional and proposed schemes, the measured impedances by the relay for both cases were different due to the injection of TCSC impedance. 


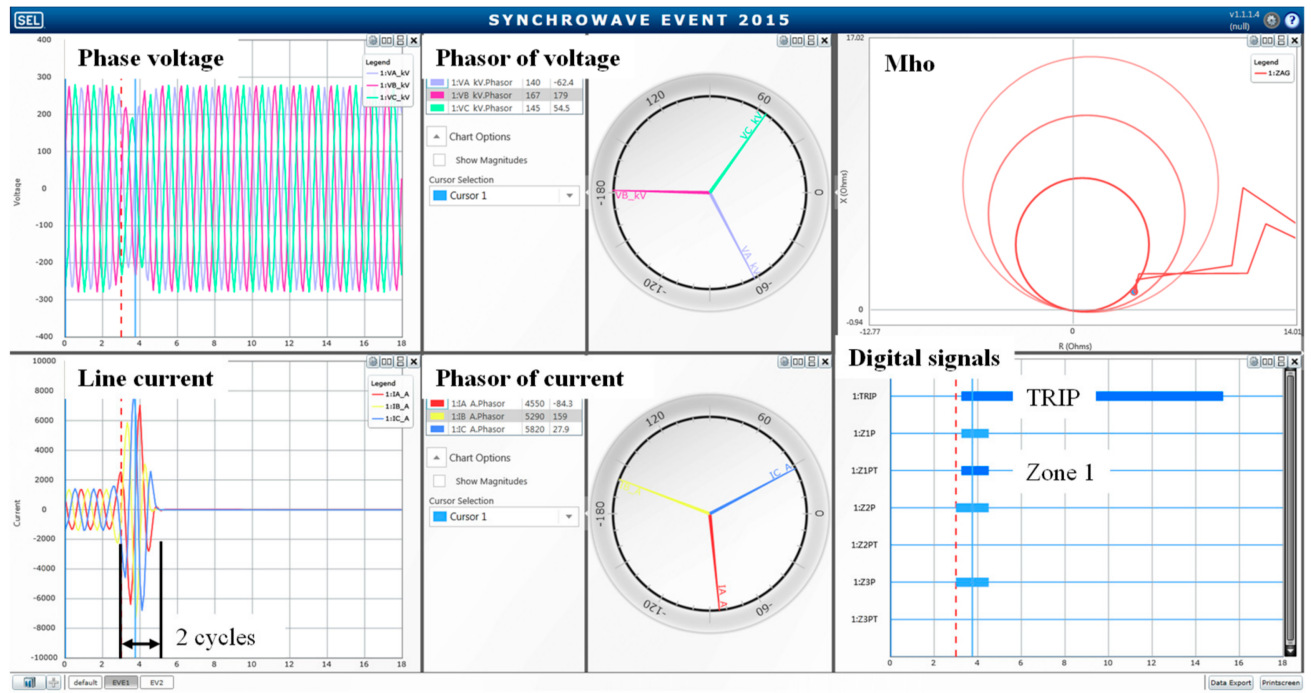

(a)

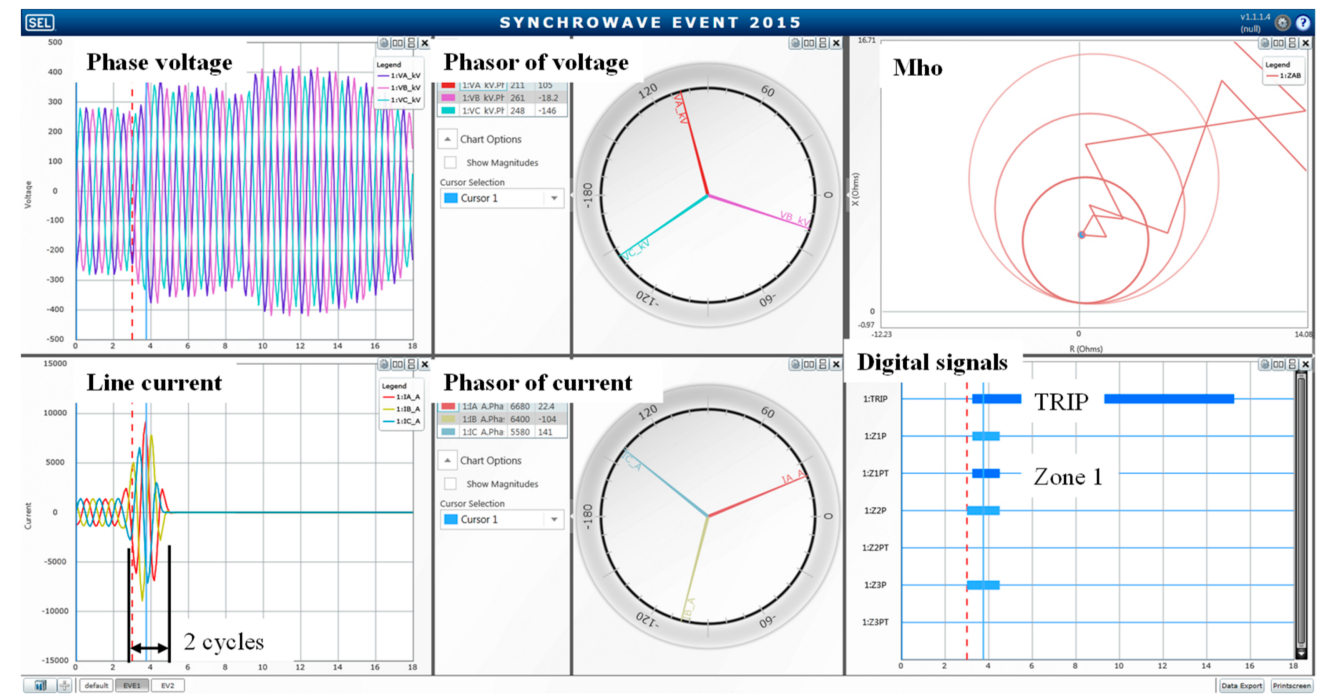

(b)

Figure 10. Event analysis of the SEL-411L for the three-phase fault at the middle of line 1: (a) without the voltage compensator scheme; (b) with the voltage compensator scheme.

Figure 11 indicates the analysis of the operating characteristics of the protection relay RA1 in the cases without and with the voltage compensator scheme during the fault at the remote end of line 1. In the case without the voltage compensator scheme, although the fault occured at the remote end of line 1, measured impedance was about 50\% of the total line 1 impedance. Thus, relay over-reaches, and it trips at zone 1 simultaneously, as shown in Figure 11a. However, as presented in Figure 11b, the measured impedance equals the total line 1 impedance. The relay trips at zone 2 with 21 cycles time delay. These results prove the correctness of the proposed voltage compensator scheme. 


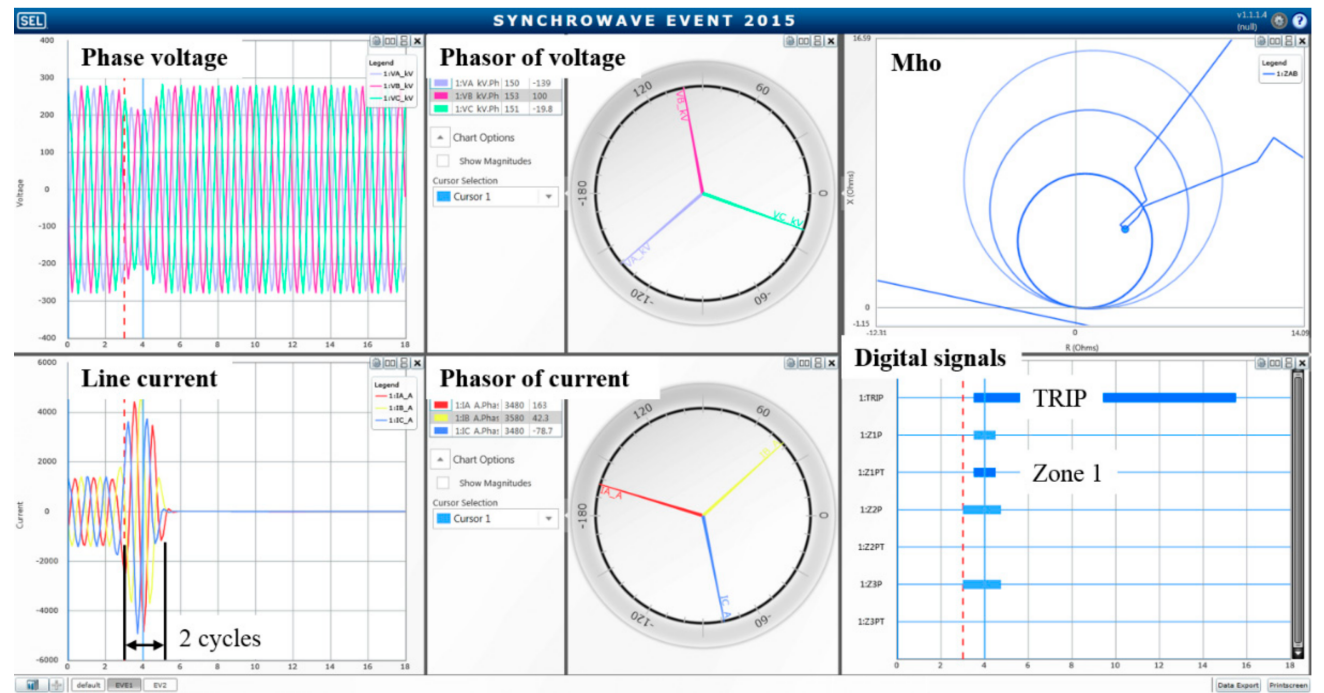

(a)

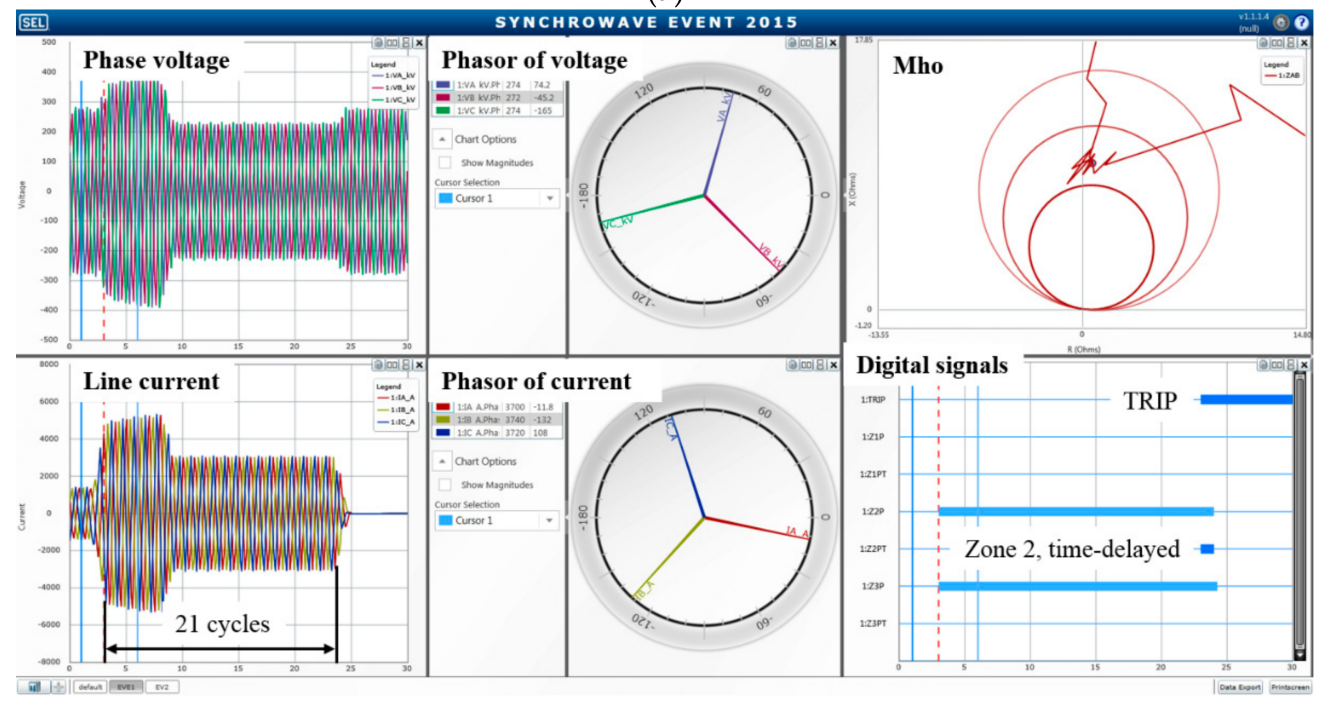

(b)

Figure 11. Event analysis of the SEL-411L for the three-phase fault at the remote end of line 1: (a) without the voltage compensator scheme; (b) with the voltage compensator scheme.

Table 8 represents the results obtained for different fault types, fault location, and power system configurations of Figure 1. The results were obtained by using the RTDS-based closed-loop test of the commercial protective relay SEL-411L. For each fault point, four different fault types (three-phase, phase-to-phase, two-phase-to-ground, and single phase-to-ground) were checked. It was assumed that load always flows from left to right.

The impact of TCSC in the protection relay is summarized in Table 8, column "original protection scheme". The commercial relay RA1 recorded the fault as three-phase instantaneous Zone 1 with the fault location up to $+90 \%$ of line 2 . This means that relay RA1 has significant over-reach for the forward faults. The same results were obtained for the other fault types (phase-to-phase, two-phase-to-ground). Zone 1 of RA1 has been extended beyond its setting at $85 \%$ of line 1 . The overshoot of the control system after the fault could increase the degree of compensation and could make the over-reach of the distance relay more serious. Zone extensions of the phase-to-ground fault are only up to $50 \%$ of line 2 .

However, as represented in Table 8, column "voltage compensator scheme", when the voltage compensator scheme is applied, the impact of TCSC on distance protection is eliminated. Also, the RA1 operates properly, as designed. RA1 trips simultaneously at Zone 1 for all fault types up to $85 \%$ of line 1. It trips at Zone 2 for faults occurring at $85 \%$ of line 2 to $50 \%$ of line 3 . If the fault point is 
beyond 50\% of line 2, the RA1 trips in Zone 3. In Table 8, "Inst." stands for "instantaneous". It means that the relay operates instantaneously. And "time" means that the relay operates with time delay. "ABC", "AB", and "ABG" denote three-phase fault, phase-to-phase fault and two-phase-to-ground fault, respectively. "AG" means single-line-to-ground fault.

Table 8. The operating characteristics of the relay RA1.

\begin{tabular}{cccccccccc}
\hline \multirow{2}{*}{ Case } & \multirow{2}{*}{$\begin{array}{c}\text { Fault } \\
\text { Type }\end{array}$} & \multicolumn{2}{c}{ Fault Location } & \multicolumn{2}{c}{ Design } & \multicolumn{2}{c}{$\begin{array}{c}\text { Original } \\
\text { Protection }\end{array}$} & \multicolumn{3}{c}{$\begin{array}{c}\text { Suggested } \\
\text { Protection }\end{array}$} \\
\cline { 3 - 9 } & & Line & Fault Point & Time & Zone & Time & Zone & Time & Zone \\
\hline 1 & & 1 & $0-50$ & Inst. & 1 & Inst. & 1 & Inst. & 1 \\
2 & AB & 1 & $50-85$ & Inst. & 1 & Inst. & 1 & Inst. & 1 \\
3 & 1 & $85-100$ & Time & 2 & Inst. & 1 & Time & 2 \\
4 & ABG & 2 & $0-50$ & Time & 2 & Inst. & 1 & Time & 2 \\
5 & ABC & 2 & $50-90$ & Time & 3 & Inst. & 1 & Time & 3 \\
6 & & 2 & $90-100$ & Time & 3 & Time & 2 & Time & 3 \\
7 & & 1 & $0-50$ & Inst. & 1 & Inst. & 1 & Inst. & 1 \\
8 & & 1 & $50-85$ & Inst. & 1 & Inst. & 1 & Inst. & 1 \\
9 & AG & 1 & $85-100$ & Time & 2 & Inst. & 1 & Time & 2 \\
10 & & 2 & $0-50$ & Time & 2 & Inst. & 1 & Time & 2 \\
11 & & 2 & $50-90$ & Time & 3 & Time & 2 & Time & 3 \\
12 & & 2 & $90-100$ & Time & 3 & Time & 2 & Time & 3 \\
\hline
\end{tabular}

\subsection{Discussion}

In this paper, the authors proposed the voltage compensator scheme to overcome the problems of the distance protection for a transmission line equipped with a TCSC. The suggested method includes the following contents.

1. In order to mitigate the impact of the TCSC in the fault loop, the TCSC injected voltage was subtracted from the measured phase voltage to obtain the compensated phase voltage. Then, the compensated phase voltage was inputted to the relay instead of the measured phase voltage.

Thus, the voltage across the TCSC should be measured and sent to the relay via a communication channel. However, the voltage across the series FACT devices, like TCSC, can be estimated based on the locally available line current using the artificial neural network (ANN), as presented in [19]. With the second approach, the communication channel can be ignored.

2. Moreover, the TCSC injected voltage was subtracted from the measured phase voltage only when the TCSC belonged to the fault loop. Thus, we needed an algorithm that could detect whether or not the TCSC is in the fault loop. Inspired by the differential protection scheme, we suggested the detection of the TCSC in the fault loop algorithm and control logic in Section 3.2.2. However, another method can be used, as presented in [13]. A method of line impedance measurement at multiple frequencies revealed that it is possible to figure out whether or not the series compensated device is in the fault loop.

3. In this paper, the compensated phase voltage was implemented in the RTDS and inputted directly to the processing module of the relay SEL-411L. The conventional distance relay needs to be upgraded to handle the subtraction $v(t)-v_{T C S C}(t)$ and addition control logic presented in Section 3.2.2.

The proposed method can mitigate the effect of the TCSC in the fault loop and secure the proper operation of distance relay in all possible operation modes of the TCSC without modifying the relay setting. However, the drawback of the proposed method is that a communication channel and additional protection devices are needed. We think that the proposed method is very close to practical.

In order to verify the proposed scheme, we only used the MHO distance relay for testing the relay RA1. In the future, quadrilateral and polygonal characteristics of distance relay are expected to be implemented to verify the proposed scheme. The reverse protection function of distance relay or the effect of the fault resistance will be considered in future work. 


\section{Conclusions}

In this paper, the authors analyzed the impact of a TCSC on the protection of transmission systems during a fault. The analysis was done by the detailed modeling of the power system and the FSC and TCSC using RTDS and the RTDS-based closed-loop test bed of a commercial protective relay. The operation characteristics of the affected distance relay were analyzed in both cases: the conventional protection scheme and the suggested voltage compensator scheme. The results indicate that the TCSC had a significant impact on the distance protection, like over-reach. However, the suggested voltage compensator scheme that subtracts the voltage across the TCSC from the measured phase voltage can overcome these problems well. It was confirmed successfully using the RTDS-based closed-loop test of the SEL-411L. The distance relay employed the suggested voltage compensator scheme operated adequately in all cases.

Author Contributions: Conceptualization, methodology, validation, writing-original draft preparation, writing - review and editing, M.-C.D.; software, M.-Q.T. and J.-I.L.; investigation, S.-J.L.; project administration, C.H.L. and J.Y.; supervision, M.P.

Funding: This work was funded by Korea Electric Power Corporation.

Conflicts of Interest: The authors declare no conflict of interest.

\section{Nomenclature}

\begin{tabular}{|c|c|}
\hline $\mathrm{C}$ & Capacitance of TCSC capacitor $(\mu \mathrm{F})$ \\
\hline$L$ & Inductance of TCR inductor $(\mathrm{mH})$ \\
\hline$X_{C}$ & Minimum reactance of $\operatorname{TCSC}(\Omega)$ \\
\hline$X_{L}$ & Reactance of TCR inductor $(\Omega)$ \\
\hline$X_{\text {TCSC }}$ & Controlled TCSC reactance $(\Omega)$ \\
\hline$V_{T C S C}$ & TCSC injected voltage $(\mathrm{kV})$ \\
\hline$E_{\text {MOVmax }}$ & Maximum MOV energy (MJ) \\
\hline$E_{\mathrm{MOV}}$ & Measured MOV energy (MJ) \\
\hline$R_{\mathrm{MOV}}$ & MOV resistance $(\Omega)$ \\
\hline$i_{\mathrm{MOV}}$ & MOV current (kA) \\
\hline$v_{\mathrm{MOV}}$ & MOV voltage $(\mathrm{kV})$ \\
\hline$i_{\text {ref }}$ & Current reference for MOV V-I characteristic curve (kA) \\
\hline$v_{\text {ref }}$ & Voltage reference for MOV V-I characteristic curve $(\mathrm{kV})$ \\
\hline$L_{d}$ & Inductance of current limiting reactor in CB bypass branch $(\mathrm{mH})$ \\
\hline$I_{\text {rated }}$ & Rated line current $(\mathrm{kA})$ \\
\hline$I_{L}$ & Measured line current $(\mathrm{kA})$ \\
\hline$Z_{m}$ & Measured impedance by distance relay $(\Omega)$ \\
\hline d & Fault location (p.u) \\
\hline$Z_{T C S C}$ & Total TCSC impedance $(\Omega)$ \\
\hline$Z_{1 L 1}, Z_{2 L 1}, Z_{0 L 1}$ & Positive-, negative- and zero-sequence impedances of line $1(\Omega)$ \\
\hline$Z_{1 L 2}$ & Positive-sequence impedance of line $2(\Omega)$ \\
\hline$Z_{1 T C S C}, Z_{2 T C S C}, Z_{\text {OTCSC }}$ & Positive-, negative- and zero-sequence impedances of $\operatorname{TCSC}(\Omega)$ \\
\hline$k$ & Compensation degree (\%) \\
\hline$I_{A}, I_{B}, I_{C}$ & Three-phase currents of transmission line $(\mathrm{kA})$ \\
\hline$V_{a}, V_{b}, V_{c}$ & Three-phase voltages of transmission line $(\mathrm{kV})$ \\
\hline$I_{1}, I_{2}, I_{0}$ & Symmetrical components of measured current by relay $(\mathrm{kA})$ \\
\hline$V_{1}, V_{2}, V_{0}$ & Symmetrical components of measured voltage by relay $(\mathrm{kV})$ \\
\hline$V_{1 T C S C}, V_{2 T C S C}, V_{\text {OTCSC }}$ & Symmetrical components of TCSC voltage (kV) \\
\hline$V_{1 \text { comp }}, V_{2 \text { comp }}$ & Symmetrical components of compensated voltage (kV) \\
\hline$K_{0}$ & Zero-sequence compensation (ZSC) factor \\
\hline$K_{01}$ & Zone $1 \mathrm{ZSC}$ factor \\
\hline$K_{O F}$ & Forward ZSC factor \\
\hline$T_{1 D}, T_{2 D}, T_{3 D}$ & Time delay of protection zone 1,2 , and 3 (cycle) \\
\hline
\end{tabular}




\section{References}

1. Li, Y.; Li, Y.; Li, G.; Zhao, D.; Chen, C. Two-stage multi-objective OPF for AC/DC grids with VSC-HVDC: Incorporating decisions analysis into optimization process. Energy 2018, 147, 286-296. [CrossRef]

2. Hingorani, N.G.; Gyugyi, L. Understanding FACTS: Concepts and Technology of Flexible AC Transmission Systems; IEEE Press: Piscataway, NJ, USA, 2019.

3. Siemens. Discover the World of FACT Technology; Siemens AG: Munich, Germany, 2011.

4. Zellagui, M.; Chaghi, A. Impact of TCSC on measured impedance by MHO distance relay on $400 \mathrm{kV}$ Algerian transmission line in presence of phase to earth fault. J. Electr. Syst. (JES) 2012, 8, 273-291.

5. Khederzadeh, M.; Sidhu, T.S. Impact of TCSC on protection of transmission lines. IEEE Trans. Power Deliv. 2006, 21, 80-87. [CrossRef]

6. Jamali, S.; Kazemi, A.; Shateri, H. Distance relay over-reaching due to installation of TCSC on next line. In Proceedings of the 2006 IEEE International Symposium on Industrial Electronics, Montreal, QC, Canada, 9-13 July 2006.

7. Liu, Q.; Wang, Z.; Xu, Y.Study on the influence of TCSC on fault component distance protection. In Proceedings of the IEEE/PES Transmission and Distribution Conference \& Exhibition, Dalian, China, 18 August 2005.

8. Kazemi, A.; Jamali, S.; Shateri, H. Distance relay over-reaching in presence of TCSC on next line considering MOV operation. In Proceedings of the 45th International Universities Power Engineering Conference (UPEC), Cardiff, UK, 31 August-3 September 2010.

9. Zellagui, M.; Chaghi, A. Impact of TCSC on distance protection setting based modified particle swarm optimization techniques. Int. J. Intell. Syst. Appl. 2013, 6, 12-24. [CrossRef]

10. Maori, A.; Tripathy, M.; Gupta, H.O. An advanced compensated Mho relay for protection of TCSC transmission line. In Proceedings of the 6th IEEE Power India International Conference (PIICON), Delhi, India, 5-7 December 2014.

11. Sidhu, T.S.; Khederzadeh, M. TCSC impact on communication-aided distance-protection schemes and its mitigation. IEE Proc. Gener. Transm. Distrib. 2005, 21, 714-728. [CrossRef]

12. Hashemi, S.M.; Hagh, M.T.; Seyedi, H. High-speed relaying scheme for protection of transmission lines in presence of thyristor-controlled series capacitor. IET Gener. Transm. Distrib. 2014, 8, 2083-2091. [CrossRef]

13. Novosel, D.; Phadke, A.; Saha, M.M.; Lindahl, S. Problems and Solutions for Microprocessor Protection of Series Compensated Lines. In Proceedings of the 6th International Conference on Developments in Power System, Nottingham, UK, 25-27 March 1997.

14. Shadriari, S.A.A.; Abardeh, M.H.; Varjani, A.Y.; Mohamadian, M. Using Fault Current Limiter to Minimize Effect of Thyristor Controlled Series Capacitor on Over Reach Problem of Distance Protection. In Proceedings of the 2009 IEEE/PES Power System Conference and Exposition, Seattle, WA, USA, 15-18 March 2009.

15. Dinh, M.; Park, S.; Kim, S.; Park, M.; Yu, I. Suggestion of a novel PHILS method for operation analysis of a thyristor controlled series capacitor. In Proceedings of the 2015 IEEE 11th International Conference on Power Electronics and Drive Systems, Sydney, NSW, Australia, 9-12 June 2015.

16. RTDS Technologies Inc. RTDS Manual; RTDS Technologies Inc.: Winnipeg, MB, Canada, 2018.

17. Pilotto, L.A.; Bianco, A.; Long, W.F.; Edris, A. Impact of TCSC control methodologies on sub-synchronous oscillations. IEEE Trans. Power Deliv. 2003, 18, 243-252. [CrossRef]

18. Lee, S.R.; Yoon, J.; Kim, J.; Yang, B.; Lee, B. Protective relay tests of a hybrid SFCLs in a Korean distribution power system using RTDS. IEEE Trans. Appl. Supercond. 2011, 21, 2188-2192. [CrossRef]

19. Jiang, J.A.; Lin, Y.H.; Yang, J.Z.; Too, T.M.; Lin, C.W. An adaptive PMU based fault detection/location technique for transmission lines-Part II: PMU implementation and performance evaluation. IEEE Trans. Power Deliv. 2000, 5, 486-493. [CrossRef]

(C) 2019 by the authors. Licensee MDPI, Basel, Switzerland. This article is an open access article distributed under the terms and conditions of the Creative Commons Attribution (CC BY) license (http://creativecommons.org/licenses/by/4.0/). 